\title{
Educação, escola e matemática escolar: sentidos dos professores de matemática da educação básica
}

\author{
Elenilton Vieira Godoy ${ }^{1}$ \\ ORCID: 0000-0001-8081-5813 \\ Fabio Gerab² \\ ORCID: 0000-0001-7869-8048 \\ Vinício de Macedo Santos ${ }^{3}$ \\ ORCID: 0000-0002-7608-8745
}

\section{Resumo}

A formação inicial do professor de matemática tem sido objeto de discussão nas esferas governamentais e nas Sociedades Brasileiras de Educação Matemática e de Matemática. Por consequência disso, percebe-se avanços em alguns pontos críticos, dentre os quais destaca-se - o excesso de matemática acadêmica desarticulada da matemática escolar; e - a aproximação das tendências teórico-metodológicas da educação matemática com a organização curricular dos cursos de licenciatura em matemática. Todavia, ainda estão ausentes as conversas envolvendo as distintas e variadas dimensões que interferem no processo de ensino e aprendizagem da matemática escolar; e as diferentes teorias do currículo. Em virtude disso, a neutralidade do conhecimento matemático e a excessiva preocupação com a dimensão normativa do currículo continuam sendo protagonistas na formação inicial do professor de matemática. Neste sentido, o presente artigo teve como objetivo investigar aspectos relacionados à percepção e entendimento de professores da disciplina de matemática na educação básica, acerca das disciplinas escolares, da escola, da educação escolar e do ser professor de matemática. Metodologicamente, incluiu-se numa abordagem quali-quantitativa de pesquisa, na qual, para alcançar os objetivos do projeto, realizou-se junto aos professores de matemática da rede pública do estado de São Paulo uma pesquisa de campo, por meio de questionário disponibilizado no "google docs". Teoricamente, fundamentou-se em estudos sobre teorias do currículo. Mostrou-se tangível que os professores colaboradores ainda estão muito presos à dimensão normativa do currículo, priorizando sempre o que ensinar, como ensinar e como avaliar, sem se preocuparem com outras dimensões (cultural, social, política) que interferem na organização curricular da matemática escolar.

\section{Palavras-chave}

Formação do professor de matemática - Estudos curriculares - Saberes escolares Matemática escolar.

1- Universidade Federal do Paraná, Curitiba, PR, Brasil. Contato: elenilton@ufpr.br

2- Centro Universitário FEl, São Bernardo do Campo, SP, Brasil. Contato: prifgerab@fei.edu.br

3- Universidade de São Paulo, São Paulo, SP, Brasil. Contato: vms@usp.br 


\section{Education, school and school mathematics: meanings of the basic education mathematics teachers*}

\section{Abstract}

The mathematics teacher initial training has been the subject of discussion in the governmental spheres and in the Brazilian Societies of Mathematical Education and of Mathematics. As a consequence of this, we notice advances in some critical points, among which stands out - the excess of academic mathematics disarticulated from the school mathematics; and - the approximation of the mathematics education theoreticalmethodological trends with the mathematics undergraduate courses curricular organization. However, there are still absent the conversations involving the different and varied dimensions that interfere in the teaching and learning process of school mathematics; and the different curriculum theories. As a result, the neutrality of mathematical knowledge and the excessive concern with the normative dimension of the curriculum continue being protagonists in the mathematics teacher initial training. In this sense, this article aimed to investigate aspects related to the perception and understanding of basic education mathematics teachers about the school subjects, the school, the school education and about being a math teacher. Methodologically, it is included in a quali-quantitative research approach, in which, in order to achieve the project's objectives, a field research, through a questionnaire available in the "Google docs", was carried out with the public network mathematics teachers from São Paulo state. Theoretically, it was based on studies about curriculum theories. It was tangible that the collaborating teachers are still very attached to the normative dimension of the curriculum, always prioritizing what to teach, how to teach and how to evaluate, without worrying about other dimensions (cultural, social, political) that interfere in the curriculum organization.of the school mathematics.

\section{Keywords}

Mathematics teacher training - Curriculum studies - School knowledge - School mathematics.

\section{Introdução}

Nos últimos anos, a formação inicial do professor de matemática tem sido objeto de discussão tanto das esferas governamentais quanto das Sociedades Brasileiras de Educação Matemática e de Matemática, por consequência, se ainda não temos um modelo de formação inicial isento de críticas, então pelo menos avançamos nas discussões envolvendo, por exemplo: a) o excesso de matemática acadêmica sem a devida articulação com a matemática escolar que será praticada, em sala de aula, pelo futuro professor; b) a aproximação das tendências teórico-metodológicas da educação matemática com a organização curricular dos cursos de licenciatura. 
Dois pontos que, do nosso ponto de vista, merecem maior atenção, nas discussões e nos debates sobre a formação inicial do professor de matemática, dizem respeito às distintas e variadas dimensões que interferem no processo de ensino e aprendizagem da disciplina escolar matemática; e às diferentes teorias do currículo.

A nossa primeira filiação teórica a respeito das teorias do currículo foi a classificação dada por Tomas Tadeu da Silva $(2000,2007)$ às diferentes teorias curriculares - tradicional, crítica e pós-crítica - que partiu da noção de discurso para construir e classificá-las, isto é, como o currículo tem sido defınido, caracterizado, em diferentes épocas e em diferentes teorias, e quais são as perguntas que essas teorias ou discursos curriculares procuram responder.

As diferentes teorias do currículo buscam respostas e argumentos para discutirem e justificarem os conhecimentos que devem ser ensinados para que os sujeitos sejam modelados de acordo com o pensamento ideológico dominante da época, ou conheçam e governem a si mesmos e à sociedade em que vivem (SILVA, 2000, 2007).

Ainda sobre os sentidos discursivos produzidos a respeito das teorias do currículo, a questão envolvendo as relações de poder contribui para a separação-distinção das teorias tradicionais - que desejam ser neutras, científicas e desinteressadas -, das críticas e pós-críticas do currículo - que negam a neutralidade-científica-desinteressada das teorias tradicionais, afirmando que, inevitavelmente, as teorias estão envolvidas em (por) relações de poder. A distinção entre as teorias também é percebida pelos diferentes conceitos empregados por cada uma delas. Inicialmente, o deslocamento da ênfase dos conceitos didáticos-pedagógicos dos processos de ensino-aprendizagem para os conceitos de ideologia-hegemonia-resistênciapoder provocou a ruptura com a teoria tradicional-teoria crítica; quando se visibilizou os conceitos de discurso-governança-desconfiança e borrou-se, principalmente, os conceitos de ideologia-hegemonia-resistência, as teorias pós-críticas do currículo recontextualizaram a maneira de perceber-conceber o currículo (SILVA, 2000, 2007).

No tempo-presente incorporamos Pinar (2007) aos nossos interlocutores e rasuramos a expressão teorias de currículo. Em seu lugar a expressão estudos curriculares produz outros registros discursivos ampliando a compreensão da centralidade desse campo para pensar educação-currículo-disciplina-conhecimento-saber adjetivadas pela escola. É uma prática discursiva interdisciplinar da experiência educativa (PINAR, 2007).

A teoria do currículo é um campo de estudo distinto, com uma história única, um presente complexo, um futuro incerto. Discerniveis neste campo singular são as influências de disciplinas das áreas das humanidades e das artes e, em menor grau, das ciências sociais (principalmente a teoria social). (PINAR, 2007, p. 18).

De acordo com Pinar (2007), a estrutura interdisciplinar do campo do currículo influenciada, sobremaneira, pelas humanidades e artes, proporciona às teorias de currículo distinta especialização na ampla área educacional.

Como campo interdisciplinar distinto [...], os Estudos Curriculares podem ser a única disciplina acadêmica dentro do campo mais alargado da educação. [...]. Somente a teoria do currículo tem a sua origem e deve a sua lealdade à disciplina e à experiência da educação. (PINAR, 2007, p. 18 - 19). 
Neste sentido, segundo Pinar (2007), a teoria do currículo é a crítica ao processo educacional contemporâneo e às suas reformas.

De facto, a "experiência educacional" parece precisamente aquilo que os políticos não querem, quando insistem em realçar as notas dos testes, os "rendimentos brutos". Ao relacionarem o currículo com o comportamento dos alunos nos exames padronizados, os políticos passaram, de facto, a controlar o que tem de ser ensinado: o currículo. Os currículos orientados para os exames despromovem os professores de acadêmicos e intelectuais a técnicos ao serviço do Estado. A cultura da autorreflexão, da erudição interdisciplinar e da intelectualidade desaparece. Racionalizada como "prestação de contas”, a socialização política substitui a educação. (PINAR, 2007, p. 19).

0 fenômeno das avaliações externas parece ser universal e a sua naturalização tende a se concretizar. Cada vez mais essas avaliações tornam-se elementos do cotidiano das nossas salas de aulas e a impressão que se tem é a de que pouca ou quase nenhuma reflexão "crítica" sobre elas são realizadas nos interiores das escolas. Professores e alunos passam a ser apenas reféns delas.

Concordamos com Pinar (2007, p. 19) sobre o fato de que o tempo presente é "um pesadelo para os professores das escolas públicas".

A escola tornou-se uma fábrica (ou empresa) de competência e de conhecimento; o professorado é reduzido ao estatuto de supervisor. Enquanto nas escolas, todos os dias, milhões vivem o pesadelo, muito poucos parecem perceber que estão a dormir. (PINAR, 2007, p. 19).

A partir das considerações feitas, justifica-se a necessidade de visibilizar, aos professores que ensinarão matemática, que a neutralidade do conhecimento científico, em particular do conhecimento matemático e a excessiva preocupação com a dimensão normativa do currículo precisam ser ressignificadas, revisitadas e reconceitualizadas. "Como ensinar isso ou aquilo?" ainda é uma pergunta comum em momentos de formações de professores, principalmente, continuadas. Perguntas do tipo "O que almejamos ao ensinar isso ou aquilo?", "Por que estes conteúdos e não outros?" raramente surgem quando de cursos de formação de professores (sejam eles na fase inicial ou continuada). Todavia, comentários, muitas vezes feitos por professores que ocupam determinados cargos nas Secretarias de Educação (SEs), “ah, os professores não querem cursos teóricos”, “o professor precisa conhecer mais matemática”, são mais comuns do que se possa imaginar. $\mathrm{Na}$ contramão de tais discursos, a professora doutora Célia Maria Carolino Pires, numa entrevista concedida a Britis (2017), no final do ano de 2016, considerou que:

[...] nos descuidamos da formação teórica do professor. Às vezes, pensávamos assim, “o professor não precisa saber teoria, ele não precisa conhecer a pesquisa que deu origem a esse tipo de trabalho com a Álgebra ou com a Geometria, ele só precisa ser o reprodutor". Esse foi o grande equívoco da formação!

0 professor precisa ter conhecimentos teóricos, não aquela teoria que ele não sabe o que fazer com ela, mas uma teoria que dialogue com a prática dele, que explique que o aluno tem esse 
ou aquele tipo de dificuldade, indicando o que os professores podem fazer para favorecer a aprendizagem e, consequentemente, para torná-la significativa. 0 embasamento teórico melhora a prática docente.[...].

Mas, como sempre, falta discussão teórica na Universidade e nos cursos de Licenciatura, nos próprios mestrados e doutorados. A falta de discussão nos deixa vulneráveis e, às vezes, superficiais nos debates sobre as questões educacionais. (PIRES, 2017 apud BRITIS, 2017, p. 110 e 111).

Concordamos com a professora Célia M. C. Pires (2017 apud BRITIS, 2017) e acrescentamos que a ausência de discussões ou de uma disciplina que discuta teorias de currículo deixa ainda mais vulneráveis os professores, neste caso, de matemática da educação básica. Mais naturalizados ficam os discursos sobre as avaliações externas e a excessiva preocupação com a dimensão normativa do currículo de matemática.

Para reforçar e delinear um pouco mais o cenário que estamos construindo está o fato de que outras dimensões, envolvendo a organização curricular da matemática escolar, são desnaturalizadas e muitas vezes tratadas como alegoria nas aulas de matemática. 0 que se espera do professor de matemática é que ele apenas ensine e discuta conteúdos associados à transposição didática da matemática acadêmica e nada além disso. Tal comentário (muitas vezes discursados de maneira não tão academicizada assim) reflete uma visão oblíqua sobre o papel do professor de matemática. Discussões associadas às dimensões social, cultural, política são, simplesmente, silenciadas a partir disso.

Os estudos curriculares também se debruçam sobre a questão do poder, pois quando se seleciona e privilegia certo tipo de conhecimento em detrimento de outro, bem como ao se destacar uma determinada identidade ou subjetividade, se exercita o poder.

Acreditamos que seja, justamente, a questão do poder que permitirá estabelecer importante e necessária aproximação com as diferentes dimensões que atuam no processo de ensino e aprendizagem da disciplina escolar matemática, pois ao colocar a ênfase na dimensão formativa, poder-se-á inculcar, na mente daqueles que estão em processo de formação, que o conhecimento matemático escolarizado é neutro, logo não se articula com as relações de poder presentes na sociedade contemporânea.

Consideramos que, ao privilegiar a dimensão formativa dos processos de ensino e aprendizagem da matemática institucionalizada pela educação escolar, contribui-se para que o saber matemático continue sendo visto como descontextualizado, despersonificado e despersonalizado. Ao privilegiar tal dimensão há, naturalmente, o silenciamento das dimensões que evidenciam o conhecimento matemático como uma prática social, carregada de significados, portanto, uma prática de significação discursiva.

Pensando no currículo escolar a partir de Pinar (2007, p. 290), ele será "o que as gerações mais velhas escolhem dizer às gerações mais novas. Qualquer que seja a disciplina escolar, o currículo é histórico, político, racial, genderizado, fenomenológico, autobiográfico, estético, teológico e institucional”, ou seja, o currículo é uma conversa complicada.

Em vez de usar o conhecimento escolar para complicar a compreensão de nós mesmos e da sociedade em que vivemos, os professores são forçados a "instruir" os alunos a imitarem as conversações dos outros (isto é, os autores de manuais), assegurando que imensas salas de aula 
estão cheias de formas de ventriloquismo, em vez de exploração intelectual, admiração e temor (HUEBNER, 1999 apud PINAR, 2007, p. 290).

A citação acima permite refletir e questionar o quanto se tem contribuído para a compreensão dos professores em formação a respeito do entendimento de que o currículo não é uma lista de conteúdos matemáticos, muito menos simbolizado pela dimensão normativa. 0 currículo como uma conversa complicada está muito distante do cotidiano da vida escolar e (ousamos afırmar) de muitas salas de cursos de formação (inicial ou continuada) dos professores, neste caso, dos professores que ensinam matemática.

Por isso, acreditamos ser importante a discussão sobre os estudos curriculares em disciplinas de graduação (licenciaturas e pedagogia, por exemplo), bem como de mestrados, doutorados e cursos de especialização. Possivelmente, apenas assim será possível potencializar a conversação complexa acerca do currículo e apresentar caminhos plausíveis para se responder perguntas como as formuladas por Pinar (2007).

Por que não são os professores autorizados, encorajados, mesmo, a mostrar aos alunos que o conhecimento acadêmico não é auto-suficiente, que frequentemente, interage em relação e de volta à vida como os seres humanos vivem? Por que não é o currículo escolar uma provocação para os alunos reflectirem sobre ela e pensarem criticamente sobre eles mesmos e o mundo que vão herdar? (PINAR, 2007, p. 291).

\section{Objetivos, hipóteses e questões norteadoras}

A proposta de aproximar os estudos curriculares, a formação de professores que ensinam matemática e os saberes escolares, mais especificamente, o saber escolar matemático nos é cara, pois aceitamos que o conhecimento e aprofundamento das diferentes teorias do currículo, pelos professores, pode contribuir para que o docente perceba e entenda o papel desempenhado por ele e pelo saber escolar matemático, independentemente, da época. Neste sentido, o presente artigo teve como objetivo investigar quais são os sentidos, atribuídos por um grupo de professores de matemática da educação básica a respeito: i) dos saberes escolares, das disciplinas escolares, das escolas e da educação; ii) do que é ser professor de matemática da educação básica no Brasil; iii) do papel desempenhado pela matemática escolar na formação dos estudantes na sociedade contemporânea.

Para tanto, trabalhamos com duas hipóteses, quais sejam: 1) o professor, particularmente, de matemática, conhece pouco sobre quais são e o que dizem as teorias do currículo. Ponderamos que o professor conheça apenas a dimensão normativa do currículo, ou melhor, que considere o currículo um plano de formação constituído por objetivo, conteúdo a ser ensinado, metodologia e avaliação; 2) o mito da neutralidade, tanto da educação quanto das disciplinas escolares, ainda sobrevive nas mentes docentes da educação básica.

A partir do nosso objetivo e das nossas hipóteses, construímos as seguintes questões norteadoras: 1. Quais são as crenças e concepções dos professores de matemática, da educação básica, a respeito da educação, da escola e do saber matemático? 2. 0 que é ser 
professor de matemática da educação básica no Brasil? 3. Qual é o papel desempenhado pela disciplina escolar matemática na formação dos estudantes na sociedade contemporânea?

\section{O percurso metodológico do estudo}

Para a consecução do objetivo proposto realizamos uma pesquisa de campo junto aos professores em exercício da rede pública do estado de São Paulo, por meio de uma parceria com a Escola de Formação e Aperfeiçoamento dos Professores - "Paulo Renato Costa Souza" (EFAP) da Secretaria Estadual de Educação (SEESP). 0 questionário foi disponibilizado aos professores, pela EFAP, no endereço https://goo.gl/forms/SoBbsmeE0ise9xv2 e respondido por 192 professores (1\% da população de professores de matemática da Secretaria Estadual de Educação de São Paulo), no período de 23/8/2017 a 23/11/20174.

0 questionário composto de 28 perguntas (abertas e fechadas), sendo 12 em escala de Likert, 2 abertas, 8 métricas e 6 categóricas ( 2 nominais e 4 ordinárias), foi dividido em quatro partes - Parte 1: Concepções docentes (Q1 a Q12); Parte 2: Sobre o ser professor (Q13 e Q14); Parte 3: Caracterização do perfil docente (Q15 a Q21); e Parte 4: 0 trabalho docente (Q22 a Q28).

\section{Metodologia de análise estatística}

As análises estatísticas foram realizadas com o auxílio do software estatístico SPSS (IBM SPSS Statistics v.19). Da análise estatística realizada, neste artigo, nos debruçaremos sobre os resultados associados à análise descritiva das questões em variáveis Likert, Ordinal e Métrica. A análise descritiva permitiu, principalmente, para as questões Likert, mediante a análise dos parâmetros de posição, dispersão e forma das suas distribuições de frequência, verificar o comportamento global de respostas para as questões.

\section{A análise descritiva}

\section{A caracterização do perfil docente dos participantes da pesquisa}

A caracterização do perfil docente está associada à Parte 3 do questionário. A questão 15 refere-se à idade; a 16 ao gênero; a 17 à Diretoria de Ensino; e as questões 18, 19, 20 e 21 à formação acadêmica. Neste sentido, a idade média dos professores participantes foi de 44,9 anos, com um desvio-padrão de 8,9 anos. Em relação ao gênero, 50\% se declarou do gênero feminino, 48,4\% do gênero masculino e 1,6\% de outro gênero. No que diz respeito à Diretoria de Ensino, 19,3\% são da Grande São Paulo, 54,2\% do Interior, 2,6\% do Litoral e 24\% do município de São Paulo. Por fim, as questões associadas à formação acadêmica indicaram que 50,5\% possuem apenas graduação, 41,7\% especialização, 5,7\% mestrado, 1,6\% doutorado e 0,5\% não respondeu.

4- Agradecemos à EFAP, mais especificamente, ao Adriano José Marangoni, à Melissa Resende Batistela e à Silente Kuin pela valiosa e imprescindível colaboração. Sem eles, com certeza, a pesquisa de campo não teria alcançado o número de professores que contribuíram com o estudo. 


\section{O trabalho docente}

0 trabalho docente está associado à Parte 4 do questionário. As questões 22 e 23, associadas à carga horária de trabalho semanal dos docentes, indicaram que a carga horária média semanal é de 36 horas, com um desvio padrão de 14 horas. Em relação ao tempo de magistério dos docentes, nos diferentes níveis de ensino, os professores participantes da pesquisa possuem maior experiência nos ensinos fundamental e médio, e menor experiência na Educação de Jovens e Adultos (EJA) e no Ensino Superior.

A análise nos permitiu concluir que em relação ao gênero há equilíbrio entre masculino e feminino, bem como entre a formação acadêmica, ou seja, o percentual de professores graduados está bem próximo do percentual de professores que possui pós-graduação. Por fim, em relação ao trabalho docente, há pouca diferença entre a distribuição de carga horária envolvendo os ensinos fundamental e médio. Os professores possuem pouca experiência com a EJA e com o Ensino Superior.

\section{Análise das questões em escala de Likert}

\section{Concepções docentes: 0 saber escolar}

As questões em escala de Likert foram construídas a partir de cinco pontos, sendo: 1 (Concordo plenamente); 2 (Concordo); 3 (Não concordo, nem discordo); 4 (Discordo) e 5 (Discordo plenamente), ou seja, para cada uma das questões (Q1 a Q12) apresentava-se a assertiva e, na sequência, os cinco descritores.

A parte 1 refere-se às concepções docentes acerca dos saberes escolares, da escola, da educação e das disciplinas escolares. Inicialmente, faremos uma análise descritiva das questões Q1, Q2 e Q3 que estão associadas aos saberes escolares e que foram construídas a partir das ideias de um conjunto de teóricos (CHEVALLARD, 1991; CHERVEL, 1990; VALENTE, 2003; PRESTE, 1996), conforme apresentado no Quadro 1.

Quadro 1- Assertivas associadas aos saberes escolares

Fonte: Elaborado pelos autores (2019). 
A Tabela 1 apresenta a análise descritiva das questões associadas aos saberes escolares (SAE).

Tabela 1- Estatística dos saberes escolares

\begin{tabular}{|c|c|c|c|c|c|c|c|}
\hline & Amostra & Média & Erro Padrão da Média & Mediana & Moda & Desvio Padrão & Variância \\
\hline SAE_Q1 & 192 & 3,12 & 0,086 & 3 & 4 & 1,189 & 1,415 \\
\hline SAE_Q2 & 192 & 2,95 & 0,086 & 3 & 2 & 1,186 & 1,406 \\
\hline SAE_Q3 & 192 & 3,01 & 0,088 & 3 & 4 & 1,219 & 1,487 \\
\hline
\end{tabular}

Fonte: Elaborada pelos autores (2019).

A análise indicou que os professores participantes da pesquisa não concordam, nem discordam com as assertivas associadas aos saberes escolares, ou seja, o respondente não concorda, nem discorda que o saber escolar é a transposição didática de um saber de referência, muito menos um saber produzido na escola e para a escola. Da mesma forma, ao responder que não concorda, nem discorda, o professor, sujeito da pesquisa, não se posiciona a respeito de como ele compreende os saberes institucionalizados pela matemática escolar.

\section{Concepções docentes: as disciplinas escolares, as escolas e a educação escolar}

As assertivas das questões (Q4 a Q12) foram construídas a partir das teorias tradicionais (Q4, Q7 e Q10), críticas (Q5, Q8 e Q11) e pós-críticas (Q6, Q9 e Q12).

\section{Análise descritiva das questões (Q4 a Q12)}

Os Quadros 2, 3 e 4 apresentam as respectivas assertivas associadas às disciplinas, escolares (DIE), às escolas (ESC) e à educação (EDE).

Quadro 2- Assertivas associadas às disciplinas escolares

\begin{tabular}{|l|}
\hline Questão (Q4) \\
As disciplinas escolares transmitem a herança cultural, auxiliam nas metas propostas à educação, servem para o amadurecimento cognitivo \\
do aluno, suas finalidades apresentam fortemente objetivos per se, e possuem caráter de neutralidade. Per se: locução (isto é, uma expressão) \\
latina que significa 'por si só', 'em si mesmo', 'intrinsecamente'. \\
\hline Questão (Q5) \\
As disciplinas escolares produzem conhecimento poderoso, apresentam em sua forma interesses sociais de uma pequena fatia da sociedade, \\
são responsáveis pelo controle social e econômico exercido pela educação escolar, e não possuem caráter de neutralidade. \\
\hline Questão (Q6) \\
As disciplinas escolares são uma ferramenta poderosa de regulação social, são um tipo de tecnologia disciplinadora, seus conhecimentos se \\
entrelaçam como o mundo institucional para produzir relações de poder (epistemologia social), e não possuem caráter de neutralidade.
\end{tabular}

Fonte: Elaborado pelos autores (2019). 
Quadro 3- Assertivas associadas às escolas

\section{Questão (Q7)}

As escolas cada vez mais são reconhecidas como agências do progresso social - pois quando são descobertas deficiências em qualquer aspecto da vida social, as chamam para eliminar tais deficiências - principalmente, pelos empresários que são os primeiros a pedir auxílio das escolas quando algo não caminha bem no seu campo profissional.

Questão (Q8)

A escola não é uma instituição neutra, pois embora elas sirvam, de fato, aos interesses de muitos indivíduos, elas também atuam empiricamente como agentes poderosos na reprodução social e cultural.

Questão (Q9)

A escola não é uma instituição neutra, uma vez que é por meio dela que o Estado educa e sanciona os conhecimentos os quais devem ser aprendidos pelos estudantes, para que estes possam ter uma visão de si e do mundo.

Fonte: Elaborado pelos autores (2019).

\section{Quadro 4- Assertivas associadas à educação}

Questão (Q10)

A educação escolar deve fornecer a inteligência e aspirações necessárias ao desenvolvimento, promovendo a estabilidade e consistência dos resultados. A educação deve enveredar por um caminho certo, não por si própria, mas pelo progresso social.

Questão (Q11)

A educação escolar é uma forma de manutenção da hegemonia dominante. Sendo assim, a cultura escolar, traduzida pelos saberes escolares encontrados nas disciplinas escolares e difundidos pelos conhecimentos científicos e das humanidades, está envolta em relações de poder, traduzidas por meio de um conceito-chave designado "tradição seletiva". Tradição seletiva significa que "a partir de um universo inteiro de conhecimento possível, somente uma parte limitada é reconhecida como conhecimento oficial, como conhecimento "digno" de ser transmitido às futuras gerações"

Questão (Q12)

A educação escolar é uma empresa de construção social. Ela destrói o sentido comum e, como resultado, o homo torna-se educandus: para aprender ele precisa ser educado. A educação está planejada para fracassar; ela produz necessidades e sujeitos necessitados, a fim de justificar sua própria necessidade.

Fonte: Elaborado pelos autores (2019).

A Tabela 2 apresenta a estatística descritiva das questões associadas às concepções dos professores a respeito das disciplinas escolares, das escolas e da educação escolar.

Tabela 2- Estatística das questões (Q4 a Q12)

\begin{tabular}{|c|c|c|c|c|c|c|c|c|c|}
\hline & $\begin{array}{c}\mathrm{DIE}_{-} \\
\mathrm{Q} 4\end{array}$ & $\begin{array}{c}\mathrm{DIE}_{-} \\
05\end{array}$ & $\begin{array}{c}\mathrm{DIE}_{-} \\
\mathrm{Q6}\end{array}$ & $\begin{array}{c}\mathrm{ESC}_{-} \\
\mathrm{Q7}\end{array}$ & $\begin{array}{c}\mathrm{ESC}_{-} \\
\mathrm{Q8}\end{array}$ & $\begin{array}{c}\mathrm{ESC}_{-} \\
\mathrm{Q} 9\end{array}$ & $\begin{array}{c}\mathrm{EDE}_{-} \\
\mathrm{Q} 10\end{array}$ & $\begin{array}{c}\mathrm{EDE}_{-} \\
\mathrm{Q} 11\end{array}$ & $\begin{array}{c}\mathrm{EDE}_{-} \\
\mathrm{Q} 12\end{array}$ \\
\hline Amostra & 192 & 192 & 192 & 192 & 192 & 192 & 192 & 192 & 192 \\
\hline Média & 2,46 & 2,93 & 2,85 & 3,22 & 2,15 & 2,22 & 2,24 & 2,81 & 3,31 \\
\hline Erro Padrão da Média & 0,067 & 0,080 & 0,078 & 0,086 & 0,060 & 0,060 & 0,062 & 0,073 & 0,078 \\
\hline Mediana & 2 & 3 & 3 & 3 & 2 & 2 & 2 & 3 & 4 \\
\hline Moda & 2 & 4 & 2 & 4 & 2 & 2 & 2 & 2 & 4 \\
\hline Desvio Padrão & 0,932 & 1,107 & 1,080 & 1,196 & 0,833 & 0,836 & 0,859 & 1,018 & 1,076 \\
\hline Variância & 0,868 & 1,226 & 1,166 & 1,431 & 0,694 & 0,698 & 0,738 & 1,036 & 1,158 \\
\hline
\end{tabular}

Fonte: Elaborada pelos autores (2019). 
A Tabela 2 nos indicou, a grosso modo, que em relação às disciplinas escolares, os professores concordam com o fato de que as disciplinas escolares transmitem a herança cultural, auxiliam nas metas propostas à educação, servem para o amadurecimento cognitivo do aluno, suas finalidades apresentam fortemente objetivos per se, e possuem caráter de neutralidade. No que diz respeito às escolas, os professores concordam que a escola não é uma instituição neutra pois: i) embora elas sirvam, de fato, aos interesses de muitos indivíduos, elas também atuam empiricamente como agentes poderosos na reprodução social e cultural; ii) é por meio dela que o Estado educa e sanciona os conhecimentos os quais devem ser aprendidos pelos estudantes, para que estes possam ter uma visão de si e do mundo. Por fim, em relação à educação escolar, os professores concordam com o fato de que a educação escolar deve fornecer a inteligência e aspirações necessárias ao desenvolvimento, promovendo a estabilidade e consistência dos resultados. A educação deve enveredar por um caminho certo, não por si própria, mas pelo progresso social.

\section{A análise das questões abertas (Q13 e Q14)}

Em relação à análise das questões abertas (Q13 e Q14) do questionário respondido pelos professores, cabe destacar que não nos filiamos a nenhuma metodologia de análise, contudo o processo de análise foi constituído a partir da identificação das palavras-chaves que apareceram com maior frequência e, neste sentido, a unidade de registro utilizada foi o tema.

\section{Questão 13- 0 que é ser professor, em especial de matemática, da educação básica no Brasil?}

Após algumas leituras das respostas realizamos uma primeira categorização, conforme apresentado na Tabela 3. Considerando-se que os temas apresentados na Tabela 3 possuíam semelhanças por grupos, construímos uma segunda categorização, conforme a Tabela 4.

Tabela 3- Temas associados ao ser professor de matemática da educação básica: $1^{\text {a }}$ categorização

\begin{tabular}{ccc}
\hline Tema & $\vdots$ & Percentual \\
\hline Agente transformador/preparar para a cidadania & $\vdots$ & $13,1 \%$ \\
\hline Desafiador & $\vdots$ & $11,5 \%$ \\
\hline Mediador do processo de ensino-aprendizagem & $\vdots$ & $11 \%$ \\
\hline Tarefa árdua e difícil & $\vdots$ & $7,1 \%$ \\
\hline Batalhador, herói & $\vdots$ & $7,5 \%$ \\
\hline Transmissor de conhecimentos & $6,5 \%$ \\
\hline Frustrante e sofrido & $5,5 \%$ \\
\hline Ter muito preparo e capacidade & $\vdots$ & $4,6 \%$ \\
\hline Educador & $\vdots$ & $4,6 \%$ \\
\hline Construir competências e desenvolver habilidades (raciocínio) & $4 \%$ \\
\hline Persistente, sonhador e otimista & $3,6 \%$ \\
\hline Ter muita responsabilidade e comprometimento & $3,1 \%$ \\
\hline Artista, intérprete & $2 \%$ \\
\hline Vocação, dom & $\vdots$ & $7,2 \%$ \\
\hline Outras respostas & $\vdots$ \\
\hline TOTAL & $100 \%$ \\
\hline
\end{tabular}

Fonte: Elaborada pelos autores (2019). 
A análise da questão (Q13) nos revelou, do ponto de vista dos professores entrevistados, que ser professor de matemática, da educação básica, ainda é percebido, para 23,3\% dos entrevistados, "[...] como um ofício/vocação, pois é frustrante e muitas vezes sofrido. É preciso ser persistente, sonhador, otimista, mas também batalhador e herói”. A categoria transição revela que $27,1 \%$ dos participantes da pesquisa percebem o ser professor de matemática mais do que um ofício, contudo, ainda não avaliam o trabalho docente como profissionalização, pois para eles o ser professor de matemática é desafiador, tarefa árdua-difícil, é ser um transmissor de conhecimentos. Por fim, 42,4\% dos professores entrevistados posicionam o trabalho docente na categoria profissionalização, pois o ser professor de matemática precisa ter responsabilidade e comprometimento, preparo e capacidade, mediar o processo de ensino-aprendizagem, ser agente de transformação social e preparar para a cidadania, ser um educador, bem como construir competências e desenvolver habilidades.

Tabela 4- Categoriais associadas à questão (Q13): $2^{\mathrm{a}}$ categorização

\begin{tabular}{ccc}
\hline Categorias & $\vdots$ & Percentual \\
\hline OfícioNocação & $\vdots$ & $23,3 \%$ \\
\hline Transição & $\vdots$ & $27,1 \%$ \\
\hline Profissionalização & $\vdots$ & $42,4 \%$ \\
\hline Outras respostas & $\vdots$ & $7,2 \%$ \\
\hline TOTAL & $\vdots$ & $100 \%$ \\
\hline
\end{tabular}

Fonte: Elaborada pelos autores (2019).

\section{Questão 14- Qual é o papel desempenhado pela disciplina escolar matemática na formação dos estudantes na sociedade contemporânea?}

Diferentemente da questão anterior (Q13), em que as categorias foram construídas a posteriori, nesta questão, decidimos construí-las a priori e inspiradas em pesquisas produzidas por Godoy $(2010,2015)$ e Godoy e Santos (2012). As categorias, inicialmente, construídas foram: interação entre conhecimentos (matemático e cotidiano); objetivo (per se e não per se); finalidade (propedêutica, para o trabalho e cidadania); e outras.

A categoria interação entre conhecimentos tinha como objetivo investigar se o professor, sujeito da pesquisa, explicitava a relação entre o conhecimento matemático escolarizado e os saberes não escolarizados. Contudo, tal explicitação apareceu em uma única resposta, ou seja, mesmo quando o participante declarava que o papel desempenhado pela matemática escolar tinha finalidade para a vida cotidiana, por exemplo, do aluno, ele não mencionava outro conhecimento que não o próprio conhecimento matemático escolarizado.

A categoria objetivo tinha como intenção analisar se para o professor, sujeito da pesquisa, considerava que a matemática escolar tinha 'um fim em si mesma (per se)' ou se era 'um meio (não per se)' para se alcançar outros objetivos. Nesta categoria, 27\% dos entrevistados consideram que o papel da matemática escolar possui um fim em si mesmo, enquanto que 73\% consideram que ela, a matemática escolar, é um meio (ferramenta) para se alçar outros voos. Neste caso, algumas respostas indicaram que o conhecimento 
matemático era um meio para se construir competências e desenvolver habilidades, conforme mencionado nos Parâmetros Curriculares Nacionais do Ensino Médio - PCNEM (BRASIL, 1999).

A categoria finalidade, por meio dos temas 'vida cotidiana', 'aplicação prática', 'propedêutica', 'mercador de trabalho' e 'cidadania' foi construída para dar mais subsídios à categoria objetivo. Em 100\% das respostas associadas à categoria objetivo 'per se' a finalidade se relacionou ao prosseguimento dos estudos (finalidade 'propedêutica'), contudo, a finalidade 'propedêutica' também apareceu na categoria objetivo, 'não per se', conforme mostra a Tabela 5. Os temas utilizados para a construção da categoria finalidade são expressões comumente encontradas nos documentos oficiais curriculares (Propostas Curriculares, Parâmetros Curriculares Nacionais, entre outros).

Tabela 5- Categoria Finalidade (objetivos não per se)

\begin{tabular}{ccc}
\hline Tema & $\vdots$ & Percentual \\
\hline Vida Cotidiana & $\vdots$ & $31 \%$ \\
\hline Aplicação Prática & $\vdots$ & $22,5 \%$ \\
\hline Propedêutica & $\vdots$ & $9 \%$ \\
\hline Mercado de trabalho & $\vdots$ & $13 \%$ \\
\hline Cidadania & $\vdots$ & $24,5 \%$ \\
\hline TOTAL & $\vdots$ & $100 \%$ \\
\hline
\end{tabular}

Fonte: Elaborada pelos autores (2019).

Para os professores participantes da pesquisa, o conhecimento matemático, por si só (uma vez que na categoria interação entre conhecimentos 99,9\% não fez menção alguma a outros conhecimentos que não o matemático) é capaz de preparar para a vida cotidiana e para o exercício da cidadania.

Por fim, em relação à categoria outras, que representou 18\% do total das respostas dadas, os temas associados foram: 'importante/fundamental', 'Desinteressante, Obsoleto e Inútil (DOI $\left.{ }^{5}\right)$ ', 'conhecimento libertador' e 'não se aplica', e estão organizados na Tabela 6.

Tabela 6- Categoria outras

\begin{tabular}{ccc}
\hline Tema & $\vdots$ & Percentual \\
\hline Importante/Fundamental & $\vdots$ & $31,5 \%$ \\
\hline DOI & $\vdots$ & $29 \%$ \\
\hline Conhecimento Libertador & $\vdots$ & $8 \%$ \\
\hline Não se aplica & $31,5 \%$ \\
\hline TOTAL & $100 \%$ \\
\hline
\end{tabular}

Fonte: Elaborada pelos autores (2019).

5- D’AMBRÓSIO, U. Sociedade, cultura, matemática e seu ensino. Educação e Pesquisa, São Paulo, v. 31, n. 1, p. 99-120, jan./abr. 2005. 
Cabe destacar que o tema "não se aplica" foi utilizado para respostas em branco ou respostas que não tinham relação alguma com a pergunta. Apesar de representar apenas 5\% do total de respostas dadas pelos professores entrevistados, ter a disciplina escolar matemática um papel desinteressante, obsoleto e inútil na formação dos estudantes na sociedade contemporânea é algo que deve nos preocupar, principalmente, se pensarmos nos alunos que estão sendo formados por estes professores que consideram o papel da matemática escolar DOI.

\section{Algumas considerações finais}

Nas considerações finais, a partir das análises realizadas, retomaremos os nossos objetivos, hipóteses e questões norteadoras com a intenção não de apresentar respostas fechadas, definitivas, mas sim de apontar caminhos que possam contribuir para o alargamento do debate envolvendo a formação (inicial ou continuada) do professor de matemática, as teorias de currículo e o saber matemático escolarizado.

Para tanto, destacaremos alguns resultados encontrados nas análises das questões associadas aos saberes escolares, às disciplinas escolares, às escolas, à educação escolar, ao ser professor de matemática e ao papel desempenhado pela matemática escolar.

\section{Em relação aos saberes docentes}

A análise das questões associadas aos saberes escolares indicou que os professores colaboradores (participantes da pesquisa), não concordam, nem discordam que o saber escolar é a transposição didática de um saber de referência, muito menos um saber produzido na escola e para a escola. Da mesma forma, ao responder que não concordam, nem discordam, os professores colaboradores não se posicionaram a respeito de como eles compreendem os saberes institucionalizados pela matemática escolar. Neste sentido, se torna tangível considerar que o professor de matemática, durante a sua formação (inicial e/ou continuada), raramente, discutiu sobre a história e a didática das disciplinas escolares, contudo, caberia, numa outra etapa, entrevistar os professores para se ter mais elementos a respeito de suas percepções e entendimentos sobre os saberes matemáticos escolarizados.

\section{Em relação às disciplinas escolares, às escolas e à educação escolar}

A análise das questões associadas às disciplinas escolares indicou que os professores entrevistados concordam com o fato de que as disciplinas escolares transmitem a herança cultural, auxiliam nas metas propostas à educação, servem para o amadurecimento cognitivo do aluno, suas finalidades apresentam fortemente objetivos per se, e possuem caráter de neutralidade.

Já a análise das questões associadas às escolas indicou que os professores entrevistados concordam que a escola não é uma instituição neutra pois: i) embora elas sirvam, de fato, aos interesses de muitos indivíduos, elas também atuam empiricamente como agentes poderosos na reprodução social e cultural"; e ii) é por meio dela que o Estado 
educa e sanciona os conhecimentos os quais devem ser aprendidos pelos estudantes, para que estes possam ter uma visão de si e do mundo.

Por fim, a análise das questões associadas à educação escolar mostrou que os professores entrevistados concordam com o fato de que a educação escolar deve fornecer a inteligência e aspirações necessárias ao desenvolvimento, promovendo a estabilidade e consistência dos resultados. A educação deve enveredar por um caminho certo, não por si própria, mas pelo progresso social.

Em síntese, a percepção-entendimento dos professores colaboradores em relação à disciplina escolar se aproxima das teorias tradicionais do currículo; em relação à escola das teorias críticas e pós-críticas do currículo; e em relação à educação escolar das teorias tradicionais do campo do currículo.

Os estudos curriculares oportunizam conhecer como as disciplinas escolares, a escola e educação escolar são compreendidas nos diferentes espaços-tempos, logo o que podemos perceber é que pouco se tem discutido sobre a temática dos estudos curriculares nos espaços de formação (inicial e continuada) dos professores de matemática. Dentre os elementos que corroboram isso, temos que os professores colaboradores concordam com o fato de que as disciplinas escolares são neutras, mas as escolas não. As escolas são apenas instituições que promovem a educação escolarizada que, independentemente, da teoria do currículo, considera a disciplina escolar central (GODOY, 2015).

Outro ponto a ser destacado e que corrobora a primeira das hipóteses deste artigo, qual seja, de que o professor, particularmente de matemática, conhece pouco sobre quais são e o que dizem as teorias do currículo, diz respeito ao fato de que, os professores participantes da pesquisa, concordam que as escolas são agentes poderosos na reprodução social e cultural enquanto a educação escolar age pelo progresso social.

Há um longo caminho a ser explorado acerca dos saberes docentes associados tanto ao campo do currículo como às dimensões que interferem na organização curricular da matemática escolar, objeto de nossa investigação, contudo, conjecturamos que os professores, particularmente de matemática, estão muito presos à dimensão normativa do currículo, priorizando sempre o que ensinar, como ensinar e como avaliar, sem se preocuparem com outras dimensões e componentes (cultural, social, política etc.) que interferem diretamente na organização curricular da matemática escolar.

\section{Em relação ao ser professor de matemática}

A percepção-entendimento dos professores colaboradores acerca do que é ser professor, em especial de matemática, da educação básica no Brasil, ainda indica que o trabalho docente é visto como ofício/vocação por 23\% dos entrevistados, contudo, mais de 69\% dos professores entrevistados consideraram que o trabalho docente não é mais um ofício/ vocação. Tal constatação pode contribuir para que os professores dos tempos presente e futuro percebam a real necessidade de investir na sua formação, objetivando formar sujeitos que possam governar a si mesmos, que participem da construção de uma sociedade que possa incluir ao invés de excluir, e que respeitem e não apenas tolerem as diferenças. 
A formação, seja ela inicial ou continuada, do professor de matemática, do nosso ponto de vista, deveria, para além de tratar dos conteúdos matemáticos, enculturar e empoderar o professor e futuro professor, objetivando, justamente, inculcar na mente dele a importância de, ao entrar e fechar a porta da sua sala de aula de matemática, socializar os diferentes conhecimentos pulsantes das experiências dos alunos e do professor (sejam eles matemáticos ou não), com vistas a formar um indivíduo que menos se sujeita e mais se governa.

\section{Em relação ao papel desempenhado pela matemática escolar}

Por fim, em relação à análise da questão associada ao papel desempenhado pela matemática escolar na formação dos estudantes na contemporaneidade, destacaremos apenas a categoria finalidades. Para os professores colaboradores, o conhecimento matemático por si só (uma vez que na categoria interação entre conhecimentos, 99,9\% não fez menção alguma a outros conhecimentos que não o matemático) é capaz de preparar para a vida cotidiana e para o exercício da cidadania. Conjecturamos, com isso, que uma parcela significativa desses professores, ao responderem o questionário, procuraram dar as respostas que o pesquisador "esperava", contudo, tal estratégia, do nosso ponto de vista, "maquia” os dados e também indica que as relações se transferem, ou seja, em sala de aula o aluno procura dar a resposta que o professor de matemática espera; e numa pesquisa em que o professor responde perguntas, ele também procura dar as respostas que o pesquisador espera. É um círculo vicioso e que não contribui de maneira positiva para os processos de ensino e aprendizagem, muito menos para uma pesquisa. São conjecturas que, para serem refutadas ou não, precisaríamos entrevistar os professores envolvidos, contudo, mesmo assim, poucos, do nosso ponto de vista, assumiriam que procuram dar as respostas que o pesquisador espera.

\section{Referências}

BRASIL. Ministério da Educação. Secretaria de Educação Média e Tecnológica. Parâmetros curriculares nacionais: ensino médio; ciências da natureza, matemática e suas tecnologias. Brasília, DF: MEC: Secretaria de Educação Média e Tecnológica, 1999.

BRITIS, Karen G. A trajetória de uma educadora matemática paulista como curriculista e formadora de professores de matemática. 2017. Dissertação (Mestrado em Ensino de Ciências e Matemática) Universidade Cruzeiro do Sul, São Paulo, 2017.

CHERVEL, André. História das disciplinas escolares: reflexões sobre um campo de pesquisa. Teoria \& Educação, Porto Alegre, n. 2. p. 177-229, 1990.

CHEVALLARD, Yves. La transposition didactique. Grenoble: La Pensée Sauvage, 1991.

D’AMBRÓSIO, Ubiratan. Sociedade, cultura, matemática e seu ensino. Educação e Pesquisa, São Paulo, v. 31, n. 1, p. 99-120, jan./abr. 2005. 
GODOY, Elenilton Vieira. A matemática no ensino médio: a trajetória brasileira desde a década de 80 e as organizações curriculares de outros países. Práxis Educacional, Vitória da Conquista, v. 6, n. 9, p. 77-100, 2010.

GODOY, Elenilton Vieira. Currículo, cultura e educação matemática: uma aproximação possível? Campinas: Papirus, 2015.

GODOY, Elenilton Vieira; SANTOS, Vinício de Macedo. 0 cenário do ensino de matemática e o debate sobre o currículo de matemática. Práxis Educacional, v. 8, n. 13, p. 253-280, 2012.

PINAR, William. F. 0 que é a teoria do currículo? Adaptação para a língua portuguesa por Ana Paula Barros e Sandra Pinto. Porto: Editora Porto, 2007.

PRESTE, Dominique. Por uma nova história social e cultural das ciências: novas definições, novos objetos, novas abordagens. Cadernos IG-Unicamp, Campinas, v. 6, n. 1. p. 3-6, 1996. Tradução de Silvia F. de M. Figueirôa.

SILVA, Tomas Tadeu da. Documentos de identidade: uma introdução às teorias do currículo. 2. ed. Belo Horizonte: Autêntica, 2007.

SILVA, Tomas Tadeu da. Teorias do currículo: uma introdução crítica. Porto: Editora Porto, 2000.

VALENTE, Wagner Rodrigues. Saber científico, saber escolar e suas relações: elementos para reflexão sobre a didática. Revista Diálogo Educacional, Curitiba, v. 4, n. 10. p. 55-67, 2003.

Recebido em: 19.09.2019

Revisado em: 26.10.2020

Aprovado em: 09.12.2020

Elenilton Vieira Godoy é docente do departamento de Matemática, do Programa de PósGraduação em Educação em Ciências e em Matemática (PPGECM) e do Programa de PósGraduação em Educação (PPGE) da Universidade Federal do Paraná (UFPR).

Fabio Gerab é professor titular e chefe do departamento de Matemática do Centro Universitário FEl e líder do Grupo de Educação Matemática e Matemática no Ensino Superior (GEMMES).

Vinício de Macedo Santos é professor titular do departamento de Metodologia de Ensino e Educação Comparada, do Programa de Pós-Graduação em Educação da Faculdade de Educação da Universidade de São Paulo (FEUSP), líder do Grupo de Pesquisas em Educação Matemática e Educação (GEPEME-USP) e bolsista de Produtividade em Pesquisa do CNPq Nível 2. 